\title{
Customized Array Comparative Genomic Hybridization Analysis of 25 Phosphatase-encoding Genes in Colorectal Cancer Tissues
}

\author{
IZABELA LACZMANSKA ${ }^{1}$, PAWEL SKIBA ${ }^{1}$, PAWEL KARPINSKI ${ }^{1}$, \\ MAREK BEBENEK ${ }^{2}$ and MARIA M. SASIADEK ${ }^{1}$ \\ ${ }^{1}$ Genetics Department, Wroclaw Medical University, Wroclaw, Poland; \\ ${ }^{2} 1$ st Department of Surgical Oncology, Lower Silesian Oncology Center, Wroclaw, Poland
}

\begin{abstract}
Background/Aim: Molecular mechanisms of alterations in protein tyrosine phosphatases (PTPS) genes in cancer have been previously described and include chromosomal aberrations, gene mutations, and epigenetic silencing. However, little is known about small intragenic gains and losses that may lead to either changes in expression or enzyme activity and even loss of protein function. Materials and Methods: The aim of this study was to investigate 25 phosphatase genes using customized array comparative genomic hybridization in 16 sporadic colorectal cancer tissues. Results: The analysis revealed two unique small alterations: of $2 \mathrm{~kb}$ in PTPN14 intron 1 and of $1 \mathrm{~kb}$ in PTPRJ intron 1. We also found gains and losses of whole PTPs gene sequences covered by large chromosome aberrations. Conclusion: In our preliminary studies using high-resolution custom microarray we confirmed that PTPS are frequently subjected to whole-gene rearrangements in colorectal cancer, and we revealed that non-polymorphic intragenic changes are rare.
\end{abstract}

The role of protein tyrosine phosphatases (PTPs) is widely described in both normal and cancer tissues. PTPs play an important role in many cellular pathways, co-acting with protein kinases via phosphorylation and dephosphorylation in activation and deactivation of a variety of enzymes. Therefore, their impact on cancer development and progression seems undeniable (1). To date the role of PTPs

This article is freely accessible online.

Correspondence to: Izabela Laczmanska, Genetics Department, Medical University, Wroclaw, Poland. Marcinkowskiego 1, 50-368 Wroclaw, Poland. Tel: +48 0717841258, Fax: +48 0717840063 , email: iza.laczmanska@gmail.com

Key Words: aCGH, colorectal cancer, protein tyrosine phosphatases. functioning mainly as tumour suppressor genes has been described in many cancers, such as colorectal, gastric, breast, ovarian, cervical, pancreatic, prostate, thyroid and many others (2). Colorectal cancer (CRC) is one of the common causes of cancer-related deaths and therefore is once of the most intensively studied types $(1,3)$. Thus, it has been proven that genetic pathways that are altered during CRC development and progression involve genes regulated to cell growth and differentiation, apoptosis and other processes crucial for cell homeostasis (2). Major genetic mechanisms underlying either hereditary or sporadic CRC are well known, but intensive studies on molecular mechanisms influencing CRC development and progression are still ongoing. CRC is characterized by chromosomal instability, loss of heterozygosity, microsatellite instability, multiple gene mutations and also epigenetic alterations, making CRC an extremely heterogeneous disease (3).

Protein tyrosine phosphatases were also revealed as being altered in CRCs. While searching for molecular mechanisms of these alterations, chromosomal aberrations (deletions/ duplications of whole regions including PTPs), gene mutations (small intragenic deletions, point mutations), and epigenetic deregulation (promoter hypermethylation) have been observed (1, 2, 4-6).

The PTP superfamily is divided into four families depending on the amino acid sequence in their catalytic domain (1). Receptor PTPs (RPTPs), non-receptor PTPs (NRPTPs) and dual specificity phosphatases (DUSPs) that can dephosphorylate not only tyrosine but also serine and threonine residues belong to the largest class (class I), possessing a cysteine residue in their catalytic centre. Moreover, cell division cycle 14 (Cdc14) (serine and threonine specific), MAP kinase phosphatases (MPKs), slingshots (serine specific) as well as phosphatase and tensin homologs (PTENs) and myotubularins (both D3phosphoinositide specific) are also included in this class (1). 
Cysteine-based classes include class II, constituting the smallest class with low molecular weight protein tyrosine phosphatases (LMW PTPs), and class III, consisting of tyrosine/threonine specific phosphatases for cell division cycle 25 (Cdc25) enzymes. Aspartate-based class IV with tyrosine and serine phosphatase activity contains Eyes absent homolog (Eya) enzymes (1).

Array comparative genomic hybridization $(\mathrm{aCGH})$ is a molecular cytogenetic technique that is very useful and widely applied in the examination of genome imbalances. The possibility of construction of the unique aCGH design makes the aCGH technique a precise tool for searching for deletions and duplications of specific genome parts such as chromosomal regions, particular genes or exons/introns. Moreover, aCGH allows for discovery of mosaic genetic alterations if these alterations are present in at least $20 \%$ of tested cells, that is crucial for cancer analysis in which copy number alternations are often present in only a fraction of examined cells (7).

The aim of this study was to investigate 25 protein tyrosine phosphatases belonging to class I. We focused on studying receptor-like protein tyrosine phosphatases, PTEN and three DUSPs. In this group, four genes, PTPRT, PTPRZ1, PTPRQ and $P T P R M$, have been examined by our group recently and promoter hypermethylation along with copy number changing of chromosomal regions encoding PTPRT, PTPRZ1, PTPRQ and PTPRM has been revealed (5).

In the present study the aCGH custom array, covering 25 protein phosphatase genes, that were reported earlier to be altered in different cancers, was designed to enable for precise analysis of exonic/intronic deletions/duplications. We hypothesize that besides large aberrations involving whole chromosomes and chromosome arms, as shown earlier, small intragenic duplication/deletions including single exons or introns could play a role in mechanisms of colorectal cancer development and progression.

\section{Materials and Methods}

Microarray comparative genomic hybridization (aCGH) analysis was performed on 16 colorectal cancer samples. All samples were obtained from patients of the First Department of Surgical Oncology of the Lower Silesian Oncology Centre in Wroclaw, diagnosed with colon adenocarcinoma. The patients underwent surgery, and before tissue collection no chemo- or radiotherapy was applied. All subjects had a negative family history in regard to both hereditary cancer syndromes and accumulation of cancers in the family. The group consisted of 8 females and 8 males with a mean age of $64.69 \pm 8.14$ years (Table I).

All samples were molecularly characterized including analysis of: the BRAF V600E (exon 15) and K-ras (codons 12 and 13) mutations, methylator phenotype (CIMP) and microsatellite instability (MSI) (8). The study was approved by the Wroclaw Medical University Ethical Committee (Approval number $328 / 2009$ ).
Table I. Molecular characteristic of examined tissues.

\begin{tabular}{lccccccc}
\hline Tissue & Age Gender & $\begin{array}{c}\text { Tumor } \\
\text { location }\end{array}$ & MSI & $\begin{array}{c}\text { BRAF } \\
\text { mutation }\end{array}$ & $\begin{array}{c}\text { KRAS } \\
\text { mutation }\end{array}$ & $\begin{array}{c}\text { Epigenotype } \\
\text { HME/LME }\end{array}$ \\
\hline 1 & 57 & F & P & MSS & + & - & HME \\
2 & 70 & M & D & MSS & - & + & LME \\
3 & 62 & F & P & MSS & + & - & HME \\
4 & 69 & M & P & MSS & - & - & LME \\
5 & 61 & M & P & MSS & - & + & LME \\
6 & 67 & F & P & MSS & - & + & LME \\
7 & 53 & F & D & MSS & - & + & LME \\
8 & 72 & M & P & MSS & - & + & LME \\
9 & 64 & F & D & MSS & - & - & LME \\
10 & 78 & M & D & MSS & - & - & LME \\
11 & 52 & M & D & MSS & - & - & LME \\
12 & 71 & M & P & MSI & - & + & LME \\
13 & 80 & M & P & MSS & - & + & LME \\
14 & 65 & F & D & MSS & - & + & LME \\
15 & 59 & F & P & MSS & - & + & LME \\
16 & 55 & F & P & MSS & - & - & LME \\
\hline
\end{tabular}

F, Female; M, male; P, proximal; D, distal; MSS, microsatellite stability; MSI, microsatellite instability; HME, high methylation epigenotype; LME, low methylation epigenotype.

DNA isolation. DNA was isolated from cancer tissues using a QIAamp DNA mini kit (Qiagen, Hilden, Germany) following the recommended protocol. All tissues were examined histopathologically as described earlier $(4,5)$. Concentration and purity of DNA samples were checked using a NanoDrop spectrophotometer. Integrity was additionally checked by agarose gel electrophoresis. Only nondegraded samples with an A260/A280 ratio between 1.8 and 2.0 and an A260/A230 ratio greater than 2.0 were used for further analysis.

Sample labelling and microarray processing. Three hundred nanograms of each DNA sample was labelled with $\mathrm{Cy}-5$ fluorescent dye using the CGH Labelling Kit for Oligo Arrays (Enzo Life Sciences Farmingdale, New York) according to the manufacturer's protocol. As a reference genotype for hybridization $300 \mathrm{ng}$ of Human Reference DNA - Male or Female (Agilent Technologies, Santa Clara, California) was simultaneously labelled with Cy-3 dye. Hybridization of samples and processing of microarrays were performed with the standard Agilent Oligonucleotide Array-Based CGH protocol.

Microarray slide design. The examined group of phosphatases included 25 genes: PTPRT, PTPRM, PTPRZ1 and PTPRQ (examined earlier) and also PTPRA, PTPRE, PTPRF, PTPRG, PTPRH, PTPRJ, PTPRS, DUSP1, DUSP4, DUSP26, PTEN, PTP4A3, PTPN1, PTPN3, PTPN5, PTPN7, PTPN13, PTPN14, PTPN21, PTPN22 and $P T P N 23$. Two slides containing 8 custom microarrays each with 60 $\mathrm{K}$ probes for $\mathrm{CGH}$ analysis were obtained from Agilent Technologies and designed using the Agilent SureDesign platform. The design was generated with Standard Design Wizard without modification of default parameters for probes selected from database. For the 25 targets probe groups were generated and extended with additional 3,000 base regions flanking 3' and 5' end of all targets. For high resolution and accuracy the target-specific probes were designed in 
Table II. Microarray design details-target phosphatases coverage in accordance to Genome Reference Consortium human genome, build 37 (GRCh37/hg19, March 2009).

\begin{tabular}{|c|c|c|c|c|}
\hline Target ID & $\begin{array}{c}\text { Interval } \\
\text { (chromosomal localization) }\end{array}$ & $\begin{array}{l}\text { Target } \\
\text { coverage }\end{array}$ & $\begin{array}{c}\text { Total } \\
\text { probes }\end{array}$ & $\begin{array}{l}\text { Median } \\
\text { probe } \\
\text { spacing }\end{array}$ \\
\hline$D U S P 1$ & chr5:172,192,093-172,201,203 & $97.5 \%$ & 37 & 223 \\
\hline DUSP26 & $\operatorname{chr} 8: 33,445,854-33,460,624$ & $82.0 \%$ & 39 & 247 \\
\hline DUSP4 & chr8:29,187,579-29,211,267 & $96.3 \%$ & 101 & 194 \\
\hline PTEN & $\operatorname{chr} 10: 89,619,870-89,734,687$ & $87.2 \%$ & 379 & 223 \\
\hline РТP4A3 & chr8:142,399,093-142,445,554 & $94.5 \%$ & 176 & 212 \\
\hline PTPN1 & $\operatorname{chr} 20: 49,123,858-49,204,300$ & $95.1 \%$ & 282 & 240 \\
\hline PTPN13 & chr4:87,512,468-87,739,328 & $84.2 \%$ & 712 & 230 \\
\hline PTPN14 & $\operatorname{chr} 1: 214,519,039-214,728,792$ & $94.5 \%$ & 731 & 236 \\
\hline PTPN21 & chr14:88,929,122-89,024,123 & $85.1 \%$ & 295 & 237 \\
\hline PTPN22 & $\operatorname{chr} 1: 114,353,433-114,417,381$ & $85.0 \%$ & 181 & 245 \\
\hline$P T P N 23$ & chr3:47,419,491-47,457,931 & $81.5 \%$ & 111 & 242 \\
\hline$P T P N 3$ & chr9:112,134,974-112,263,593 & $94.0 \%$ & 459 & 227 \\
\hline PTPN5 & $\operatorname{chr} 11: 18,746,475-18,817,268$ & $95.3 \%$ & 249 & 242 \\
\hline PTPN7 & $\operatorname{chr} 1: 202,113,141-202,133,716$ & $93.2 \%$ & 72 & 226 \\
\hline PTPRA & $\operatorname{chr} 20: 2,841,830-3,022,320$ & $83.8 \%$ & 509 & 255 \\
\hline PTPRE & chr10:129,702,325-129,887,164 & $95.6 \%$ & 679 & 229 \\
\hline PTPRF & $\operatorname{chr} 1: 43,987,858-44,092,343$ & $97.1 \%$ & 401 & 232 \\
\hline$P T P R G$ & $\operatorname{chr} 3: 61,544,243-62,286,288$ & $95.4 \%$ & 2654 & 232 \\
\hline PTPRH & chr19:55,689,615-55,723,874 & $69.7 \%$ & 79 & 268 \\
\hline PTPRJ & chr11:47,999,110-48,195,394 & $90.3 \%$ & 623 & 245 \\
\hline PTPRM & $\operatorname{chr} 18: 7,564,314-8,409,859$ & $89.1 \%$ & 2914 & 231 \\
\hline$P T P R Q$ & chr12:80,835,126-81,076,968 & $84.3 \%$ & 799 & 230 \\
\hline PTPRS & $\operatorname{chr} 19: 5,170,977-5,343,814$ & $81.0 \%$ & 482 & 244 \\
\hline PTPRT & chr20:40,698,392-41,821,610 & $91.9 \%$ & 3922 & 231 \\
\hline PTPRZ1 & $\operatorname{chr} 7: 121,510,143-121,705,090$ & $96.3 \%$ & 723 & 232 \\
\hline
\end{tabular}

triplicate with median spacing of $233 \mathrm{bp}$. The final design of the microarray included 17609 target-specific probes for 25 selected genes covering 5.2 Mbp of the genome. The targets coverage details are shown in Table II. An additional standard set of controls, normalization and backbone probes gives a whole-genome backbone with approximately 1 probe per 1-1,5 Mbp.

Data analysis. Analysis of the results was performed with CytoGenomics software (Agilent Technologies) with the default CGH analysis method. The protocol calls an aberration as gain or loss for at least 3 continuous probes with mean signal (sample to reference) Log Ratio of at least 0.25 or -0.25 respectively. With this algorithm and microarray design the practical resolution of detected aberrations was approximately 700 bp for targeted genes and 3-5 $\mathrm{Mb}$ for the background (similar to karyotype resolution for whole chromosome analysis).

\section{Results}

Microarray analysis (chromosomal level). The analysis of chromosomal regions revealed 48 chromosomal gains in chromosomes: 1 (2 of 16 probes), 2 (2/16), 3 (1/16), 6 (1/16), 7 (7/16), 8 (9/16), 10 (1/16), 11 (1/16), 12 (6/16), 13 (7/16),
Table III. Chromosomal aberrations revealed in aCGH analysis.

\begin{tabular}{lcc}
\hline Sample & Gains on chromosomes & Losses on chromosomes \\
\hline 1 & $2,7,12,20$ & $6 \mathrm{q} 21 \mathrm{q} 22.31$ \\
2 & - & - \\
3 & $2,7,8 \mathrm{q}, 20 \mathrm{q}$ & $1 \mathrm{q} 32.1 \mathrm{q} 43,17 \mathrm{p}, 18,21$ \\
4 & - & - \\
5 & $12,13,20$ & 18 \\
6 & $7,8,12,13,19$ & - \\
7 & $1 \mathrm{q}, 6 \mathrm{p}, 7 \mathrm{q}, 8 \mathrm{q} 11.21 \mathrm{q} 21.13$, & $8 \mathrm{p}, 17 \mathrm{p}, 18,20 \mathrm{p}$ \\
& $8 \mathrm{q} 23.3 \mathrm{q} 24.13,12 \mathrm{p}, 13,16,20 \mathrm{q}$ & - \\
8 & - & $8 \mathrm{p}, 18$ \\
9 & $7 \mathrm{q}, 20$ & - \\
10 & $1 \mathrm{p}, 3,7,8,12 \mathrm{q} 21.31 \mathrm{q} 22$, & $1 \mathrm{q} 31.1 \mathrm{q} 44,8 \mathrm{p} 12 \mathrm{p} 23.3$, \\
& $12 \mathrm{q} 24.31 \mathrm{q} 24.33,13,20 \mathrm{q}$ & $11 \mathrm{q}, 17 \mathrm{p}, 18 \mathrm{q}, 22$ \\
11 & $13,20 \mathrm{q}$ & $8 \mathrm{q} 21.3 \mathrm{q} 22.1$ \\
& & - \\
12 & $8 \mathrm{p} 23.3 \mathrm{q} 21,8 \mathrm{q} 21 \mathrm{q} 24.3$ & - \\
13 & - & - \\
14 & $13, \mathrm{Xp}$ & - \\
15 & $8 \mathrm{p} 22,8 \mathrm{q}, 10 \mathrm{p}$ & \\
16 & $7 \mathrm{p}, 11 \mathrm{p}, 13,20 \mathrm{q} 11.21 \mathrm{q} 13.33$ &
\end{tabular}

16 (1/16), 19 (1/16), $20(8 / 16)$ and 19 losses in $1(2 / 16), 6$ (1/16), 8 (4/16), $11(1 / 16), 17$ (3/16), 18 (5/16), 20 (1/16), 21 $(1 / 16)$ and $22(1 / 16)$. Most aberrations covered either the whole chromosome or a whole arm (54/67) (Table III).

Microarray analysis (gene level). The analysis of targeted genes encoding tyrosine phosphatases revealed gains and losses of whole gene sequences covered by large chromosome aberrations for 22 out of 25 genes (Figure 1). No changes were observed for phosphatases: PTPN22, DUSP1, PTPN21.

Also 9 different small intragenic alterations for 8 out of 25 genes were discovered. Seven of them were classified as copy number variations (CNVs) according to the Database of Genomic Variants (Structural Variants, July 2015), while one small deletion: of $2 \mathrm{~kb}$ in PTPN14 intron 1 and one small gain of $1 \mathrm{~kb}$ in PTPRJ intron 1 were classified as unique (Table IV).

No aberration with Log Ratio greater than 1 or below -1 indicating DNA amplification (above 4 copies) or homozygous deletion respectively was observed.

\section{Discussion}

The role of receptor-type PTPs has been intensively studied in recent years because of their important role in fundamental cellular processes, crucial also for cancer development and progression. Different alterations in PTPs genes including whole-gene deletions, point-mutations, aberrant methylation pattern and changes in mRNA expression levels show that 


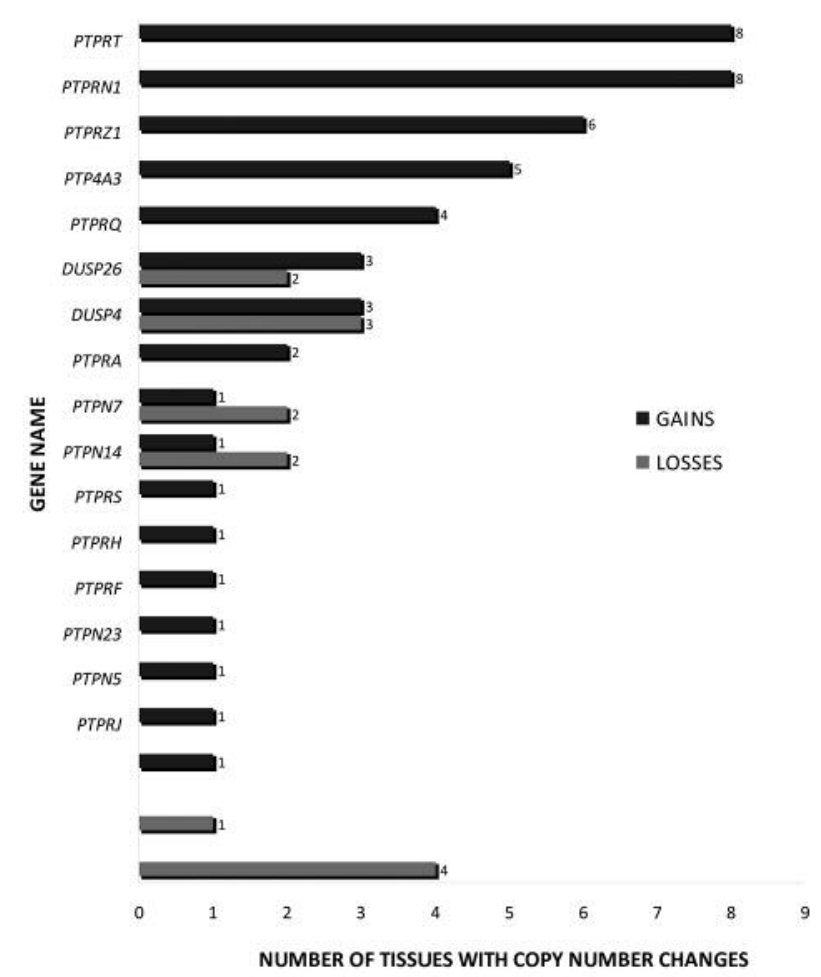

Figure 1. Summary of observed alterations (whole-gene gains and losses) in phosphatase genes revealed using custom microarray. ${ }^{*} \mathrm{CNV}$ not included.

receptor-like protein tyrosine phosphatases actively participate in cancerogenesis $(1,2,5,6)$.

We performed a custom aCGH microarray to find alterations in exons and introns of 25 selected tyrosine phosphatase genes. To the best of our knowledge, this is the first study using a custom aCGH microarray that allowed 25 different phosphatase genes to be analyzed on exonic level.

We found mainly whole-gene gains and heterozygous deletions, confirming earlier reports and suggesting that receptor-type protein tyrosine phosphatases may act as either tumour suppressor genes or proto oncogenes $(5,10)$. Also large chromosomal gains and losses found in our custom array analysis confirmed earlier results obtained from microarray and classical CGH (10).

Small alterations that were observed in PTPRG $(8 / 16$ samples), in PTPN3 (7/16) PTEN (2/16), PTPN13 (3/16), PTPRE (1/16), and also in PTPRT (1/16) (Table IV) were identified as CNVs and because of their polymorphic status there is no evidence that these alterations may play any role in splicing of the PTPs genes.

The non-polymorphic small intragenic deletion covered a part of intron 1 was observed in one sample for the PTPN14 gene ( $2 \mathrm{~kb}, 9$ probes). In two other tissues the PTPN14 whole gene deletion together with chromosomal region 1q31.1q44 covering this gene was observed. Also, we found a gain of this region in one sample. PTPN14 is a potential tumour suppressor gene whose function is not well characterized yet. It is a non-receptor PTP that was shown to be involved in cell adhesion, proliferation and angiogenesis regulation (11-13). Moreover, several PTPN14 mutations were found in breast and colorectal cancer (6). The function of PTPN14 still remains unknown, but it has been shown that this protein mediates beta-catenin dephosphorylation and epithelial-mesenchymal transition and also promotes transfer of oncoprotein yes-associated protein 1 (YAP1) from the nucleus to cytoplasm and thus inhibits its transcriptional activity $(14,15)$. Also, the loss of PTPN14 in mammary epithelium cells led to their transformation, confirming the tumour suppressor function of this gene (14).

Also, we observed the non-polymorphic small intragenic gain covering a part of intron 1 for the PTPRJ gene $(1 \mathrm{~kb}, 3$ probes) in one sample. We also found one gain on $11 \mathrm{p}$ that covered whole sequence of $P T P R J$ gene in another probe.

$P T P R J$ has been previously described as a tumor suppressor gene in colon, lung and breast cancer where loss of heterozygosity ( $\mathrm{LOH}$ ) of this gene was observed (16). Also the LOH of PTPRJ connected with its downregulation has been suggested to be a common mechanism in Non-Hodgkin's lymphoma genesis (17). The lower PTPRJ expression both on mRNA and protein levels was also reported in esophageal squamous cell carcinoma (ESCC) compared to normal cells. Moreover in ESCC PTPRJ down-regulation was correlated with advanced tumour stage and poor differentiation (18). In in vitro experiments involving a human cervical carcinoma cell line, cells with loss of PTPRJ expression showed increased cell viability, rising growth and migration rate. The opposite effect was observed in cells with PTPRJ overexpression (19). These results, all confirm the role of PTPRJ as a tumor suppressor gene.

In the contrary other researches reported that in PTPRJdeficient mice the formation of lung metastases was strongly decreased. Also, lower microvascular PTPRJ expression was observed in less vascularised tumours, what can be evidence that this gene plays a crucial role in VEGF-dependent angiogenesis and metastasis (20).

Our findings of two whole PTPN14 deletions and also two small intragenic alterations of intron 1 of PTPN14 and intron 1 of PTPRJ of unknown significance are consistent with previous results describing these genes as tumour suppressor genes. Alterations in introns may modulate splicing or arrest this process, leading to changes in gene expression or even absence of the gene product $(21,22)$.

Gains observed for both genes in two different probes may suggest their opposite role in carcinogenesis which is 
Table IV. Alterations in phosphatase genes revealed using custom microarray.

\begin{tabular}{|c|c|c|c|c|}
\hline Tissue & $\begin{array}{l}\text { Whole gene gains with } \\
\text { chromosomal region }\end{array}$ & Intragenic gains & $\begin{array}{l}\text { Whole-gene deletions with } \\
\text { chromosomal region }\end{array}$ & Intagenic deletions \\
\hline 1 & $\begin{array}{c}P T P R Z 1, P T P R Q, P T P R A, \\
P T P R T, P T P N 1\end{array}$ & $\begin{array}{l}P T P R G \text { int } 2(5 \mathrm{~kb})^{\mathrm{CNV}} \\
\text { PTPN3 ex } 1(6 \mathrm{~kb})^{\mathrm{CNV}}\end{array}$ & - & PTPN14 int1 (2kb) \\
\hline 2 & - & PTPN13 int $40(1 \mathrm{~kb}) \mathrm{CNV}$ & - & - \\
\hline 3 & PTPRZ1, PTP4A3, PTPRT, PTPN1 & $\begin{array}{l}\text { PTPRG int } 2(5 \mathrm{~kb})^{\mathrm{CNV}} \\
\text { PTPN3 ex } 1(6 \mathrm{~kb})^{\mathrm{CNV}}\end{array}$ & $\begin{array}{c}\text { PTPN7, PTPN14, } \\
\text { PTPRM }\end{array}$ & - \\
\hline 4 & - & - & - & $P T P R T$ int $7(6 \mathrm{~kb}) \mathrm{CNV}$ \\
\hline 5 & $P T P R Q, P T P R A, P T P R T, P T P N 1$ & $\begin{array}{l}\text { PTPRG int } 2(5 \mathrm{~kb})^{\mathrm{CNV}} \\
\text { PTPN3 ex } 1(7 \mathrm{~kb})^{\mathrm{CNV}}\end{array}$ & PTPRM & PTEN int $1(1 \mathrm{~kb})^{\mathrm{CNV}}$ \\
\hline 6 & $\begin{array}{c}\text { PTPRZ1, DUSP4, DUSP26, PTP4A3, } \\
\text { PTPRQ, PTPRS, PTPRH }\end{array}$ & $\begin{array}{l}\text { PTPRG int } 2(5 \mathrm{~kb})^{\mathrm{CNV}} \\
\text { PTPN3 ex } 1(7 \mathrm{~kb})^{\mathrm{CNV}}\end{array}$ & - & - \\
\hline 7 & PTPN7, PTPN14, PTPRZ1, PTPRT, PTPN1 & $\begin{array}{l}P T P R G \text { int } 2(4 \mathrm{~kb})^{\mathrm{CNV}} \\
P T P N 3 \text { ex } 1(2 \mathrm{~kb})^{\mathrm{CNV}}\end{array}$ & $\begin{array}{c}\text { DUSP4, DUSP26, } \\
\text { PTPRM, PTPRA }\end{array}$ & - \\
\hline 8 & - & $\begin{array}{l}\text { PTPN13 int } 40(1 \mathrm{~kb})^{\mathrm{CNV}} \\
\text { PTPRE ex } 20(1 \mathrm{~kb})^{\mathrm{CNV}} \\
\text { PTPRJ int1 (1kb) }\end{array}$ & - & - \\
\hline 9 & PTPRZ1, PTPRT, PTPN1 & $\begin{array}{l}\text { PTPRG int } 2(5 \mathrm{~kb})^{\mathrm{CNV}} \\
\text { PTPN3 ex } 1(7 \mathrm{~kb})^{\mathrm{CNV}}\end{array}$ & DUSP4, DUSP26, PTPRM & - \\
\hline 10 & $\begin{array}{l}P T P R F, P T P R G, P T P N 23, P T P R Z 1, D U S P 4, \\
D U S P 26, P T P 4 A 3, P T P R Q, P T P R T, P T P N 1\end{array}$ & $P T P N 3$ ex1 $(7 \mathrm{~kb}) \mathrm{CNV}$ & - & - \\
\hline 11 & PTPRT, PTPNI & $\begin{array}{l}\text { PTPRG int } 2(4 \mathrm{~kb})^{\mathrm{CNV}} \\
\text { PTPRG int } 1(0.4 \mathrm{~kb})^{\mathrm{CNV}}\end{array}$ & DUSP4, PTPN7, PTPN14 & - \\
\hline 12 & $\begin{array}{c}\text { DUSP4, DUSP26, PTP4A3 } \\
-\end{array}$ & PTPN13 int $40(1 \mathrm{~kb}) \mathrm{CNV}$ & & $P T E N$ int $1(1 \mathrm{~kb})^{\mathrm{CNV}}$ \\
\hline 13 & - & - & - & - \\
\hline 14 & - & - & - & - \\
\hline 15 & $P T P 4 A 3$ & - & - & - \\
\hline 16 & PTPN5, PTPRJ, PTPRT, PTPN1 & - & - & - \\
\hline
\end{tabular}

$\mathrm{CNV}$, Copy number variation (polymorphism).

consistent with the dual role of protein tyrosine phosphatases in carcinogenesis because of their ability either to activate or to inactivate of different enzymes.

In summary, in our preliminary study using high-resolution custom microarray we found that in the majority of cases PTPs are frequently subjected to whole-gene rearrangements in CRC, whereas non-polymorphic intragenic changes are rare.

\section{Conflicts of Interest}

None.

\section{Funding}

This study was funded by Statutory Activities financed by Ministry of Science and Higher Education, Wroclaw, Poland.

\section{References}

1 Hoekstra E, Peppelenbosch MP and Fuhler GM: The role of protein tyrosine phosphatases in colorectal cancer. Biochim Biophys Acta 1826(1): 179-188, 2012.
2 Julien SG, Dubé N, Hardy S and Tremblay ML: Inside the human cancer tyrosine phosphatome. Nat Rev Cancer 11(1): 3549, 2013.

3 Mundade R, Imperiale TF, Prabhu L, Loehrer PJ and Lu T: Genetic pathways, prevention, and treatment of sporadic colorectal cancer. Oncoscience 1(6): 400-406, 2014.

4 Laczmanska I, Karpinski P, Bebenek M, Sedziak T, Ramsey D, Szmida E and Sasiadek MM: Protein tyrosine phosphatase receptor-like genes are frequently hypermethylated in sporadic colorectal cancer. J Hum Genet 58(1): 11-15, 2013.

5 Laczmanska I, Karpinski P, Kozlowska J, Bebenek M, Ramsey D, Sedziak T, Ziolkowski P and Sasiadek MM: Copy number alterations of chromosomal regions enclosing protein tyrosine phosphatase receptor-like genes in colorectal cancer. Pathol Res Pract 210(12): 893-896, 2014.

6 Wang Z, Shen D, Parsons DW, Bardelli A, Sager J, Szabo S, Ptak J, Silliman N, Peters BA, van der Heijden MS, Parmigiani G, Yan H, Wang TL, Riggins G, Powell SM, Willson JK, Markowitz S, Kinzler KW, Vogelstein B and Velculescu VE: Mutational analysis of the tyrosine phosphatome in colorectal cancers. Science 304(5674): 1164-1166, 2004.

7 Schaaf CP, Wiszniewska J and Beaudet AL: Copy number and SNP arrays in clinical diagnostics. Annu Rev Genomics Hum Genet 12: 25-51, 2011. 
8 Karpinski P, Szmida E, Misiak B, Ramsey D, Leszczynski P, Bebenek M, Sedziak T, Grzebieniak Z, Jonkisz A, Lebioda A and Sasiadek MM: Assessment of three epigenotypes in colorectal cancer by combined bisulfite restriction analysis. Mol Carcinog 51(12): 1003-1008, 2012.

9 Kozlowska J, Karpinski P, Szmida E, Laczmanska I, Misiak B, Ramsey D, Bebenek M, Kielan W, Pesz KA and Sasiadek MM: Assessment of chromosomal imbalances in CIMP-high and CIMP-low/CIMP-0 colorectal cancers. Tumour Biol 33(4): 1015-1019, 2012.

10 Cai H, Gupta S, Rath P, Ai N and Baudis M: arrayMap 2014: an updated cancer genome resource. Nucleic Acids Res 43(Database issue): D825-30, 2015.

11 Ogata M, Takada T, Mori Y, Oh-hora M, Uchida Y, Kosugi A, Miyake K and Hamaoka T: Effects of overexpression of PTP36, a putative protein tyrosine hosphatase, on cell adhesion, cell growth, and cytoskeletons in HeLa cells. J Biol Chem 274(18): 12905-12909, 1999.

12 Wadham C, Gamble JR, Vadas MA and Khew-Goodall Y: The protein tyrosine phosphatase Pez is a major phosphatase of adherens junctions and dephosphorylates beta-catenin. Mol Biol Cell 14(6): 2520-2529, 2003.

13 Benzinou M, Clermont FF, Letteboer TG, Kim JH, Espejel S, Harradine KA, Arbelaez J, Luu MT, Roy R, Quigley D, Higgins MN, Zaid M, Aouizerat BE, van Amstel JK, Giraud S, DupuisGirod S, Lesca G, Plauchu H, Hughes CC, Westermann CJ and Akhurst RJ: Mouse and human strategies identify PTPN14 as a modifier of angiogenesis and hereditary haemorrhagic telangiectasia. Nat Commun 3: 616, 2012.

14 Wang W, Huang J, Wang X, Yuan J, Li X, Feng L, Park JI and Chen J: PTPN14 is required for the density-dependent control of YAP1. Genes Dev 26(17): 1959-1971, 2012.

15 Belle L, Ali N, Lonic A, Li X, Paltridge JL, Roslan S, Herrmann D, Conway JR, Gehling FK, Bert AG, Crocker LA, Tsykin A, Farshid G, Goodall GJ, Timpson P, Daly RJ and Khew-Goodall Y: The tyrosine phosphatase PTPN14 (Pez) inhibits metastasis by altering protein trafficking. Sci Signal 8(364): ra18, 2015.
16 Ruivenkamp CA, van Wezel T, Zanon C, Stassen AP, Vlcek C, Csikós T, Klous AM, Tripodis N, Perrakis A, Boerrigter L, Groot PC, Lindeman J, Mooi WJ, Meijjer GA, Scholten G, Dauwerse $\mathrm{H}$, Paces V, van Zandwijk N, van Ommen GJ and Demant P: Ptprj is a candidate for the mouse colon-cancer susceptibility locus Scc 1 and is frequently deleted in human cancers. Nat Genet 31(3): 295-300, 2002.

17 Aya-Bonilla C, Green MR, Camilleri E, Benton M, Keane C, Marlton P, Lea R, Gandhi MK and Griffiths LR: High-resolution loss of heterozygosity screening implicates PTPRJ as a potential tumor suppressor gene that affects susceptibility to NonHodgkin's lymphoma. Genes Chromosomes Cancer 52(5): 46779, 2013.

18 Qiao D, Li M, Pu J, Wang W, Zhu W and Liu H: Loss of protein tyrosine phosphatase receptor $\mathrm{J}$ expression predicts an aggressive clinical course in patients with esophageal squamous cell carcinoma. Pathol Oncol Res 22(3): 541-547, 2016.

19 Yan CM, Zhao YL, Cai HY, Miao GY and Ma W: Blockage of PTPRJ promotes cell growth and resistance to 5-FU through activation of JAK1/STAT3 in the cervical carcinoma cell line C33A. Oncol Rep 33(4): 1737-1744, 2015.

20 Fournier P, Dussault S, Fusco A, Rivard A and Royal I: Tyrosine Phosphatase PTPRJ/DEP-1 Is an Essential Promoter of Vascular Permeability, Angiogenesis, and Tumor Progression. Cancer Res 76(17): 5080-91, 2016.

21 Venables JP: Unbalanced alternative splicing and its significance in cancer. Bioessays 28(4): 378-386, 2006.

$22 \mathrm{Li} \mathrm{H}$, Chen D and Zhang J: Analysis of intron sequence features associated with transcriptional regulation in human gene. PLoS One 7(10): e46784, 2012. 